\title{
O Planejamento dos Lucros Para os Bancos
}

Charles C. Ellis*

3. O Sistema de Acompanhamento. 4. A Anatomia de Relatórios e Reuniöes Eficientes.

No número passado da RAE, de março de 1970 , foram publicadas as partes: 1. Porque é Necessário o Planejamento dos Lucros no Banco?; e 2. A Implantação de um Sistema Efetivo de Planejamento de Lucros. O trabalho é concluído neste número com a publicação das partes 3 e 4 .

\section{O Sistema de Acompanhamento}

A prcparação de um plano de lucros é apenas o primeiro passo para se estabelecer um sistema de planejamento de lucros. Se não se tivesse que ir mais longe, inquestionàvelmente se ganharia uma compreensão bem mais profunda dos pormenores de uma emprêsa e das pessoas que a administram. Embora êstes benefícios certamente valham o tempo e a energia despendidos em alcançá-los, êles ainda não

* Vice-Presidente Senior e Comptroller da Irving Trust Company of the City of New York. Originalmente publicado numa série de artigos na Revista Bankers Monthly, de agôsto a novembro de 1967, Chicago, EUA. Traduzido por Eduardo Matarazzo Suplicy, Professor-Assistente de Economia do Departamento de Ciências Sociais da Escola de. Administração de Emprêsas de São Paulo da Fundação Getúlio Vargas.

R. Adm. Emp., Rio de Janeiro, 10 (2): 157-175, abr./jun. 1970 
produziriam o maior objetivo do esfôrço do planejamento de lucros, especificamente, os resultados. O planejamento de lucros é apenas uma estratégia ou plano de ação para se atingir uma certa meta ou objetivo de lucro. Para se estar certo de que esta estratégia se traduzirá em ações, as quais produzirão resultados, é necessário que se desenvolva um sistema de acompanhamento efetivo.

Para se obter um sistema de acompanhamento que produza resultados, êle deverá satisfazer vários requisitos importantes.

\subsection{A MEDIDA DO PROCESSO DE FORMA OBJETIVA}

Dêstes requisitos o mais fundamental é medir-se, tão precisamente quanto possível, o progresso que se está fazendo por todos os níveis da organização em atingir os resultados planejados. Dever-se-ia indicar aquelas áreas em que os resultados planejados estão sendo obtidos, excedidos ou não alcançados, bem como medir-se a extensão das variações ocorridas. Também dever-se-ia localizar com precisão a atuação tanto por responsabilidade quanto por função.

Para a administração superior pode ser adequado se ter conhecimento de que o administrador de divisão está falhando em seu plano e de quanto. Mas ao nível dos administradores de divisão, ou abaixo dêste nível, é muito importante saber exatamente em que função se está realizando, falhando ou excedendo o seu plano. Sem esta informação a ação corretiva não pode ser iniciada.

Um bom sistema de acompanhamento também deve ser imparcial e objetivo. Uma das tarefas mais difíceis, associada ao projeto de qualquer método, para se medirem as realizações, é a incorporação de um plano imparcial que pareça justo e sem predileções para aquêles que estão sendo avaliados. Nenhum sistema de se medirem as atuações, já construído, foi estruturado de forma tão perfeita que tais questões como: "Quem é responsável por tal despesa?" ou "Quem deve ganhar crédito por tal receita?" deixem de aparecer. Sempre haverá os casos limites em que diversos administradores de departamentos podem igualmente reclamar o crédito da mesma receita, ou reclamar contra o débito de certas despesas. Geralmente, o responsável pelo contrôle é forçado a resolver muitos dêstes desarcordos. Se sua resolução é insatisfatória a um dos que reclama, ela terá que ser resolvida por um nível de administração mais alta. 
Independentemente da decisão, um dos participantes geralmente achará que foi roubado e que o árbitro foi de alguma forma não muito objetivo. O importante disto tudo é que a efetividade do sistema de se medir as realizações estará reduzida porque o perdedor acha, inevitàvelmente, que o sistema é imperfeito; assim, usa isto como desculpa para desacreditar sua produção de informações válidas, como também pode permitir que seus sentimentos pessoais para com o árbitro se adicionem ao seu desprêzo para com todo o sistema de acompanhamento.

\subsection{O ENFOQUE DA COMISSÃO DE NORMAS}

Uma maneira efetiva para se manter uma atmosfera de imparcialidade e ao mesmo tempo para introduzir um elemento democrático no sistema é a criação de um comitê de normas. Este estabelecerá as regras básicas para se medir as realizações e para arbitrar os principais casos onde as regras não proporcionem respostas claras às questões disputadas. Entre os membros desta comissão estariam incluído os administrados de divisões cujas operações estivessem sendo mantidas, assim como assistentes e representantes da administração superior.

Para se evitar que essa comissão seja muito grande e para que se mantenha representativa, poderia estabelecer-se uma base rotativa para seus membros. Desta forma muitos dos sentimentos pessoais, relacionados às decisões de avaliações, poderiam ser eliminados. Aquêles que estivessem sendo avaliados estariam muito mais cônscios das dificuldades envolvidas em se fazer tais decisões, assim como se sentiriam como uma parte do sistema que faz as decisões.

Um dos principais problemas associados com qualquer sistema da administração, que envolve a medida da realização obtida em relação a um plano, é a tendência muito normal daqueles que estão sendo avaliados de ver o sistema de acompanhamento como uma série de boletins em que êles estão obtendo notas de forma semelhantes à situação numa escola. A regra do jôgo torna-se então obter-se uma boa nota, ainda que isto signifique concentrar-se em enganar o sistema de avaliação ao invés de melhorar sua execução. Isto é o que freqüentemente origina muitas das discussões que mencionamos prèviamente, relacionadas às receitas e despesas, as quais precisam ser resolvidas por algum procedimento judicial. 
Dada a forma da natureza humana, no entanto, seria tolice tentar-se reformar aquêles que parecem ser demais orientados para o sistema de notas. De fato, êste orgulho pessoal de se conseguir uma boa nota é um dos fatôres básicos, que fazem com que um sistema efetivo de acompanhamento funcione. Sem êste incentivo, a administração, inquestionàvelmente, teria que usar de muito mais pressão para obter os resultados planejados.

\section{3. ÊNFASE NO FUTURO}

Um dos principais fatôres que contribuem para enfatizar demais o aspecto de boletim de muitos sistemas de acompanhamento, no entanto, é a atenção excessiva dada à verificação do que foi realizado no passado. O que é passado é história e não pode ser mudado. Como tal, sua revisão sòınente tem valor quando encarada como guia para se planejar os futuros caminhos de ação. No entanto, muito frequientemente a realização passada é revista minuciosamente e quase com deleite mórbido.

Extensas explicações sôbre as variações em relação ao planejado são demandadas dos administradores quase que da mesma forma que como um interrogatório de criminoso, e a preparação de justificativas e desculpas ocupa uma apreciável parte do tempo de todos os níveis administrativos. Todo sistema de acompanhamento torna-se então um longo exercício em "chorar sôbre as águas passadas".

Para evitar esta cilada, todo o sistema de acompanhamento deverá, constantemente, focalizar sua atenção sôbre o futuro, o qual, diferentemente do passado, é controlável. Ao invés de incorporar longas explanações a respeito do que estêve errado, o sistema devia estar destinado a dar ênfase àquilo que pode ser feito no futuro, à luz daquilo que tem acontecido no passado. A revisão do que foi executado no passado torna-se, então, apenas um auxílio para se determinar para onde se devem dirigir os esforços a fim de obter-se os objetivos planejados. Se se tornar aparente que será impossivel atingir tais objetivos é muito melhor que se tenha um sistema que irá concentrar-se na procura de ações futuras, alternativas que irão minimizar o efeito de planos não executáveis do que um sistema que se concentre na dramatização das falhas passadas. 


\subsection{A PREVISÃO DE RESULtAdOS}

Para se atingir esta contínua ênfase no futuro, no sistema efetivo de acompanhamento, tôdas as comparações do plano deveriam incluir não sòmente os resultados operacionais realmente ocorridos até a data presente, como também uma previsão dos resultados operacionais para o remanescente do período de planejamento o qual, em geral, é o ano. A reação imediata mais normal a esta recomendação é: "Você deve estar fora de si", "Como você pode pedir a todos os administradores para que façam todo trabalho envolvido em preparar uma nova previsão tôda vez que a execução fôr revista?", "Isto poderia ser tão freqüiente quanto uma vez por mês!".

Inquestionàvelmente, isto parece ser uma carga não razoável para os administradores se as previsões forem preparadas desde a base inicial, da mesma forma como se faz a preparação do plano anual de lucros inicial. No entanto, para se ter uma boa previsão não é necessário envolver-se em tal esfôrço. A previsão pode ser feita simplesmente por exceção ao plano de lucros anual.

Um administrador prevê sòmente as variações antecipadas em relação ao plano anual sem ficar absorvido com todos os pormenores com os quais êle se defrontou na preparação do plano original. Na prática isto pode envolver a previsão de apenas uma ou duas grandes variações com relação a um plano. Provàvelmente não seria necessário prever muitas pequenas variações ao acaso, se sua influência nos resultados operacionais forem negligentes, ou se elas tiverem pequena influência no planejamento de caminhos futuros de ação.

Esta técnica de previsão, portanto, proporciona não apenas o bènefício de ser menos trabalhosa, mas realiza a tarefa de análise como um subproduto do processo de previsão. Um administrador ao preparar a sua previsão também está analisando a sua atuação. Ao prever as variações êle obtém o benefício de saber quais foram as variações reais em relação ao plano, quais os fatôres que estão causando as variações e quais ações êle estará apto a iniciar para corrigir ou compensar estas variações. Do ponto de vista da administração superior, êste enfoque tem a vantagem de dirigir contìnuamente a atenção dos administradores para aquelas áreas nas quais êles não estão cumprindo o plano. $\mathrm{E}$ muito mais difícil para um administrador continuar prevendo as variações não favoráveis em relação ao plano, de que explicar variações 
passadas ou prever resultados operacionais futuros não relacionados com o que se planeja realizar. Ele está constantemente sob pressão para agir de forma a eliminar ou compensar por suas variações não favoráveis.

\subsection{UM PADRÃo PARA SE MEDIR A REALIZAÇÃo}

O uso consistente de apenas um padrão para se medir a realização é um outro importante requisito de um sistema efetivo de acompanhamento. Como o plano de lucros pormenoriza aquilo que planejamos fazer para atingir nossos objetivos de lucros desejados, êle é a base lógica para ser usado, ao se medirem resultados operacionais reais e previstos. O uso de outras bases de avaliação tais como comparações com anos anteriores, embora interessante, pode destruir muito da efetividade de um sistema de acompanhamento.

Os administradores se confundirão com a complexidade de se medir suas realizações tendo em vista mais de um padrão e tenderão a escolher aquêle que faça com que êles apareçam da forma mais favorável. Assim, se êles estiverem falhando em seus planos, mas se estiverem melhores do que no ano passado, geralmente irão querer falar a respeito de quão melhor estão êste ano em relação ao ano passado, e procurarão livrar-se de alguma maneira de falar sôbre a falha em relação ao plano.

O plano anual é comparado com a experiência do ano anterior, quando apresentado para aprovação da administração superior. Ao aceitar o plano, esta está ciente de sua relação com o plano anterior e, portanto, não deveria ser necessário rever esta relação cada vez que a execução real e prevista forem revistas. Este passo já deve ter sido anulado na hora em que o plano é aceito. Como a maioria dos planos mostram melhoras sôbre a experiência do ano anterior, será certamente vantajoso para a administração superior manter sua atenção voltada para a meta mais ambiciosa.

\subsection{AS REVISÕES SÃo ACONSËLHÁVEIS}

As opiniōes variam bastante respeito de um dos requisitos para a eficiência de um sistema de acompánhamento, o da frequiência das revisões da execução do plano. Em outros tipos de indústrias, afora a de 
bancos, as comparações semanais e mensais com o plano são bastante comuns. As comparações semanais cobrem em geral, apenas as despeśas operacionais diretas, enquanto que as comparações mensais incluem todos os itens de despesas e de receitas. Em bancos, por causa da natureza do negócio ser mais estável e menos influenciado por mudanças bruscas nas condições econômicas, muitos crêem que revisões trimestrais da execução em relação ao planejado são suficientes para manter um contrôle adequado. Além disso, isto requer apenas um têrço do tempo e esfôrço dispendidos em relação a uma frequiência mensal de revisões.

Embora não haja uma resposta positiva ou negativa para esta questão, é bom que se a encare tendo em vista os objetivos básicos do sistema de acompanhamento.

Ao chamar a atenção para os desvios em relação ao plano, o sistema de acompanhamento deve estimular ações que irão corrigir ou compensar aquêles desvios que tiveram um efeito desfavorável sôbre os lucros. Pareceria razoável que quanto menos demora envolvida em se chamar a atenção do administrador para êstes desvios, menos tempo se perderia para planejar e iniciar a ação corretiva. Embora a atividade bancária possa, em geral, ser considerada como mais estável do que a de muitas outras indústrias, os bancos têm experimentado recentemente algumas mudanças violentas em seu meio ambiente durante períodos de tempo relativamente curtos. Quanto mais rápido o sistema de acompanhamento possa reagir ao efeito de tais mudanças, melhor se estará preparado para iniciar quaisquer cursos novos de ação necessários para enfrentá-las.

Parece então, que um acompanhamento mensal da execução do planejado deve ser mais eficiente do que uma frequiência mensal. Embora o trabalho total seja inquestionàvelmente maior do que se fôsse feita a revisão trimestralmente, é bem menos do que a razão aparente de três para um. Como a maior parte dos registros contábeis são feitos numa base mensal, muito dos dados necessários para as revisões semestrais podem ser obtidos como um subproduto do fechamento contábil.

Uma outra razão para se ter uma freqüência maior do que a trimestral é a importância de se ter a atenção focalizada nos objetivos planejados. Mostrar-se a execução real e prevista em relação a êstes objetivos doze vêzes ao ano ao invés de quatro (uma das quais pro- 
vàvelmente se dará na época de férias) deve (ontribuir muito para manter esta atenção.

Após examinarmos os requisitos de um sistema de acompanhamento, deveremos ver a seguir os principais meios de comunicação empregados para satisfazer tais requisitos. Dois meios de comunicações são essenciais para o sucesso de um sistema de acompanhamento: relatórios e reuniões. Embora muitos sistemas pareçam funcionar com apenas um dêsses meios, a eficiência ótima só será atingida se ambos forem usados.

\subsection{O VALOR DOS RELATÓRIOS ESCRITOS}

Um relatório possui a vantagem de apresentar tôda a informação pertinente de uma maneira acessível prontamente. Se um administrador deseja rever os dados de seu comportamento, basta tirar o relatório de sua gaveta ou pasta e lê-lo. Não precisa se lembrar do que viu ou do que the foi dito numa reunião. Esta vantagem de pronta acessibilidade também proporciona a desvantagem de fàcilmente se arquivar e se esquecer. Se um relatório é recebido em hora em que parece haver assuntos bem mais urgentes para serem resolvidos, pode ser que seja convenientemente arquivado e esquecido até o próximo mês em que o próximo relatório é recebido e semelhantemente pôsto de lado porque nova safra de assuntos urgentes demandam novamente tôda a atenção do tempo do administrador. Pode ser que, sòmente quando uma catástrofe ocorrer na área de execução do plano, o administrador finalmente irá pegar os relatórios a fim de tentar verificar o que está acontecendo.

Uma outra desvantagem de um relatório como único meio de comunicação é a demora envolvida em se obter respostas às questões levantadas pelas informações nêles incluídas.

Se o dia do administrador no escritório está preenchido com as exigências mencionadas anteriormente, êle pode, se consciencioso, recorrer à leitura do relatório em sua condução para casa, ou em casa. Se achar importantes questões levantadas pelas informações apresentadas, êle terá que anotá-las na margem do relatório e, se se lembrar de olhá-las na manhã seguinte, antes de se enredar noutro dia típico no escritório, êle terá que entrar em contato com aquêles que, segundo pensa, podem responder suas perguntas. Isto poderia ser um projeto 
para um dia e portanto, provàvelmente, será abandonado antes que mais de uma ou duas respostas sejam obtidas.

\subsection{A SUPLEMENTAÇÃO POR REUNIÕES}

A adição de uma reunião de revisão do que foi realizado, ao sistema de acompanhamento, ao menos minimizará êste problema. Como a participação nestas reuníóes provàvelmente incluirá todos os administradores cujas execuções estiverem sendo revistas, deverá ser possível obter-se uma resposta imediata à maioria das questões levantadas. Se uma resposta imediata não fôr possível, a tarefa de obtê-la pode ser fàcilmente dada ao administrador responsável.

Trazer tais questões à atenção de um grupo e não apenas à de um administrador é um benefício adicional de uma reunião de revisão das reailzações. Muito frequientemente a discussão é resultante de uma questão dirigida a um administrador que revela problemas mútuos não reconhecidos que poderiam ser melhor resolvidos simplesmente por uma mudança na política da emprêsa. Também, a solução de um problema visto por um administrador pode ter sido achada por um outro que, no entanto, não teria outra oportunidade de revelar aos demais, não fôsse pela reunião.

Estas discussões também proporcionam uma excelente oportunidade para a administração fazer com que suas normas sejam mais claramente compreendidas por outros membros do grupo administrativo. À médida que problemas específicos são apresentados e soluções recomendadas são discutidas, a administração superior pode definir de forma mais clara suas normas ao aplicá-las às circunstâncias reais envolvidas em cada caso. Desta forma, os administradores de divisões estarão obtendo uma definição operacional das normas e objetivos da emprêsa ao invés de simplesmente expressos em têrmos abstratos e remotos em relação às situações reais.

Provàvelmente a maior vantagem da inclusão de uma reunião de revisão no sistema de acompanhamento seja sua eficiência no estimular ações corretivas. Neste ponto, a vantagem da reunião sôbre o relatório é quase que inteiramente psicológico. Quase todos administradores, embora não gostem de admitir falhas e de apresentar excusas por suas fracas exibições para seus administradores, acham que 
isto é menos difícil e humilhante do que ter que fazer o mesmo diante de seus companheiros.

Portanto, se um administrador sabe que mês após mês terá que fazer as mesmas admissões de suas falhas na presença de seus colegas administradores, êle provàvelmente estará muito mais fortemente estimulado a tomar alguma atitude para corrigir a situação. Para a administração superior isto oferece o benefício adicional de não precisar recorrer a ser duro a fim de exigir ação de alguns membros do grupo administrativo. Algumas palavras brandas de desprazer com o realizado por um administrador na frente de seu grupo conseguirá, provàvelmente, resultados bem maiores do que um ataque violento ao seu comportamento privado.

O sistema de acompanhamento é o sistema que permite à administração traduzir seus planos de lucro em ações. Como tal, êle deveria empregar todos os meios possíveis para encorajar todos os níveis administrativos e atingir as metas estabelecidas nos planos. Examinamos os principais requisitos de um sistema de acompanhamento destinado a satisfazer êste objetivo e recomendamos os meios de comunicação que o sistema deve empregar.

\section{A Anatomia de Relatórios e Reuniões Eficientes}

Antes de abordarmos os fatôres específicos envolvidos na preparação de relatórios dirigidos para a ação e de reuniões de análises e revisão, é essencial reconhecer que estamos embarcando num grande esfôrço de vendas.

Geralmente, aquêles que preparam informações para serem apresentadas em relatórios e reunióes acreditam, ingênuamente, que as pessoas para as quais as informações são dirigidas, estão aguardando ansiosamente aquelas informações e consumirão àvidamente todo fragmento de dados que fôr amontoado perante essas pessoas. Infelizmente, tudo isto está muito longe da verdade.

Os que recebem tais informações se não estiverem desinteressados, pelo menos estarão muito atarefados, tendo, geralmente, coisas urgentes para fazer e muito pouco tempo para executá-las. Eles não estarão aguardando informações para estimulá-los para a ação. Como consequiência, o requisito primordial de um meio de disseminar infor- 
mações efetivas é conseguir e manter a atenção dos indivíduos para os quais as informações são dirigidas.

\subsection{UM TRABALHO DE VENDEDOR}

Para se ter sucesso, ao se fazer isto, é preciso vender as informações, não apresentá-las. Portanto, nós deveríamos seguir tôdas as regras do jôgo de vendas. Uma das mais importantes destas é "conhecer o seu cliente". Tudo o que se fizer deveria estar condicionado pelo conhecimento do pessoal para o qual se está dirigindo a mensagem. Se acontecer de ser alguém que goste de dados negativos em vermelho, que se dêem a êle dados em vermelho; não tente convencê-lo de que os dados entre parênteses ou com sinais negativos são mais práticos, se isto diminuir o impacto das informações que se estão apresentando.

Por esta razão, nenhuma das técnicas ou formatos sugeridos que forem descritos nas sessões seguintes podem ser recomendados incondicionalmente. Os gostos individuais dos que recebem as informações devem sempre ser considerados. E preciso lembrar que o maior objetivo é o de atingir resultados, e não o de criar trabalhos de arte, ou de melhorar os gostos estéticos da audiência.

Lembrando dêste objetivo e reconhecendo que sempre há ocasiões em que algumas pessoas parecem responder apenas àquilo que mais viola as regras da boa apresentação, pode-se começar a olhar aquelas coisas que geralmente caracterizam os relatórios e as reuniões de revisão eficientes.

\subsection{OS RELATÓRIOS PRECISAM SER ATRATIVOS}

Provàvelmente o atributo mais importante e menos reconhecido de um relatório eficiente é a sua aparência global ou o que se pode chamar de sua primeira impressão de qualidade. Muito freqüentemente êste fator determinará se o leitor irá se importar de ler além da primeira página. Embora não seja preciso recomendar todos os meios de persuasão empregados nas capas de novelas, há muitas técnicas bizarras e mais sutis que podem ser usadas para atrair o leitor potencial.

PROPORÇão E dimensão - Uma destas é a proporção. Sendo os parágrafos ou gráficos exatamente do tamanho correto, numa posição 
correta numa página. Embora isso pareça altamente subjetivo e possa requerer um ôlho artístico para produzir, cria impressão de qualidade e profissionalismo à qual a maioria das pessoas responderão favoràvelmente. Parágrafos que são muito altos ou muito baixos numa página, ou margens que são muito largas ou muito estreitas, criam uma impresssão de amadorismo que o leitor tenderá também a associar ao conteúdo do relatório.

Outro fator relacionado com a proporção é a dimensão do relatório. Aqui o leitor potencial é não apenas influenciado pela estética da proporção, mas também por considerações práticas, tais como se o relatório cabe ou não numa pasta ou numa gaveta de escrivaninha. Se não couber numa pasta pode ser que nunca seja lido porque o receptador normalmente faz tôdas as suas leituras em casa; não cabendo numa gaveta de escrivaninha aquêle que o recebe pode deixar de lê-lo porque precisa guardá-lo num armário inconveniente de ser usado. Se fôr de um tamanho diferente de todos os outros relatórios pode se tornar uma fonte de perturbação considerável que poderia culminar, realmente, num forte desgôsto pelo relatório em si mesmo.

Por causa destas considerações utilitárias é melhor que se fique relativamente perto do tamanho padrão de papel de, aproximadamente, ' $22 \mathrm{~cm}$ por $30 \mathrm{~cm}$. Isto também proporciona benefício adicional de economia, porque papel de tamanho fora do padrão é, geralmente, muito mais caro.

POR'MENORES TÉCNICOS - Há muitos outros fatôres que contribuem para a aparência geral de um relatório. Estes incluem o estilo do tipo, a clareza e alinhamento do tipo, a qualidade das cópias, a forma de dobrar, a qualidade do papel, a grafia, a gramática e uma porção de outros pormenores. Qualquer um dêstes itens, aparentemente inconsequiente, no entanto, é capaz de destruir a eficiência de um relatório, que de outra forma seria excelente. $O$ autor certa vez viu o principal executivo de uma grande companhia ferver à medida que lia com dificuldade um relatório, cujo fecho da capa escondia parte das palavras do lado esquerdo da margem de cada página. Não é preciso dizer que êste pormenor bastante trivial afetou sèriamente a apreciação de todo o trabalho que havia sido feito ao se preparar o conteúdo do relatório, e a mensagem que êste continha foi quase que pràticamente obscurecida pelas emoções que foram originadas. 


\subsection{A IMPORTÂNCIA DA BREVIDADE}

De igual importância como aparência geral na criação de um relatório eficiente, é a brevidade. Aquêles que recebem os relatórios de execução do plano de lucros são administradores que, geralmente, estão pressionados pelo tempo e, portanto, sentem que não podem despender horas valiosas lendo com dificuldade grande massa de dados e de figuras. Reconhecendo-se isto, torna-se essencial fazer relatórios que atingirão os seus resultados intencionados com um mínimo absoluto de dados.

Há duas maneiras principais pelas quais esta brevidade desejada pode ser atingida sem se perder a eficiência dos relatórios. Uma delas é a seleção de informar e a outra é a condensação de informações.

SELEÇÃo DE INFORMAÇão - A seleção de informação é essencialmente o adaptar a informação apresentada num relatório para a pessó que o recebe. Isto significa que em vez de se mandar o mesmo relatório a todos, um tipo separado de relatório é preparado para cada nível da administração. Estes relatórios contêm apenas informações que são relevantes ao nível administrativo ao qual elas são dirigidas.

A seleção de informação apresentada a cada nível administrativo é baseada na maneira pela qual êste contrôle é realmente exercido em cada nível. Se o principal diretor exerce seu contrôle fazendo com que cada administrador de divisão seja responsável pelo comportamento dos lucros de sua divisão, um simples relatório mostrando apenas as variações ao redor do lucro planejado para cada divisão e para o banco como um todo pode ser adequado.

Se êle desejar informações mais minuciosas sôbre o comportamento de uma divisão em particular, êle pode achar muito mais satisfatório que isto seja apresentado e explicado pelos administradores de divisão do que se fornecido um relatório muito mais volumoso, do qual êle teria que tentar extrair a informação por si mesma.

Descendo através da estrutura organizacional, cada administrador de divisão receberia um relatório mostrando as variações em relação à receita e à despesa planejada por cada departamento de sua divisão. Da mesma forma, cada um de seu administradores de departamentos receberia um relatório das variações sôbre o plano de cada um de seus itens de receita e de despesa. Em geral, quanto mais baixo o nível 
administrativo, mais minuciosa é a informação apresentada. $O$ administrador de divisão, por exemplo, pode receber as variações sôbre o plano, apenas das principais categorias de despesas para cada um dos departamentos em sua divisão; enquanto que cada administrador de departamento receberia as variações dentro de cada uma dessas categorias de despesas de forma pormenorizada.

Isto pode ser visualizado como uma pirâmide de relatórios, com muitos relatórios contendo informações bastante pormenorizadas na base, e um número menor de relatórios com informações mais gerais a cada nível sucessivamente mais alto. Desta forma a cada administrador é dada sòmente a informação necessária para que êle possa controlar as suas áreas próprias de responsabilidade.

Esta seleção de informação prevê não apenas um grande passo em direção a se atingir brevidade, mas também faz com que os relatórios sejam mais eficientes, ao eliminar informações desnecessárias que tenderiam a distrair ao invés de auxiliar os administradores em atingir seus objetivos planejados.

CONDENSAÇÃO DE INFORMAÇõES - Um outro fator importante para se obter brevidade é a condensação de informações ou o uso de um número mínimo de palavras ou dados que dêem a maior quantidade de informações.

Uma das maneiras mais simples para se reduzir o número de dados em um relatório é o de deixar de lado os centavos e arredondar os cruzeiros em centenas, milhares ou milhões, dependendo da importância dos números que estão sendo relatados. Mostrar num relatório de execução de planejamento de lucros que o banco ganhou $\mathrm{NCr} \$$ 1.898.326,52 pode nada significar a mais do que se se mostrasse em milhares como NCr\$1.898,3 ou em milhões como NCr\$1,9. Ao se decidir qual a maneira de se apresentar êste dado, a escolha deveria estar baseada no uso que se fará do mesmo.

Se, nesta instância, deve ser comparado com o lucro planejado de NCr\$ 1.845.750,00 não seria desejável, òbviamente, se dar uma informação como NCr\$1,9 milhões porque assim não se possibilitaria mostrar uma variação favorável em relação ao plano de $\mathrm{NCr}$ \$ $45.576,52$.

Se a informação tivesse sido expressa em milhares, no entanto, a variação poderia ser mostrada como $\mathrm{NCr} \$ 45,6$. E difícil de se ver 
como qualquer coisa se ganharia com maior minúcia além dêste ponto. Certamente uma variação de $\mathrm{NCr} \$ 45,6$ milhares deveria ser tão significativa para efeito de contrôle como uma informação de $\mathrm{NCr} \$$ 45.576,52 e economizamos 4 algarismos e um ponto neste processo.

Uma outra forma de se reduzir os dados apresentados sem se perder qualquer informação, é eliminar-se figuras isoladas que nada contribuem para a mensagem transmitida pela informação no relatório. Por exemplo, reportar-se um dado real, um dado planejado e um dado de variação nada diz a mais ao leitor do que reportar-se apenas um dado real e um dado de variação. O dado planejado, no caso, adiciona de significação ao relatório. Apesar disso, muitas pessoas que preparam relatórios de variações parecem compelidas a mostrar tanto o dado real como o planejado em adição à variação.

Há muitas outras formas pelas quais as informações podem ser condensadas quando apresentadas em relatório, tais como: o agrupamento de categorias não importantes de receitas e despesas, relacionando-se apenas os itens em que existem variações, etc. $O$ grande obstáculo de sucesso nesta área parece ser uma urgência irresistível por parte daqueles que preparam os relatórios de querer incluir todos os dados de sua fôlha de trabalho para preparar o relatório. Isto, provàvelmente, resulta do mêdo de que êles não gozarão de crédito por todo o trabatho que foi feito para realizar o relatório se apresentassem apenas alguns dados significativos.

Se fôr necessário incluir pormenores consideráveis num relatório, isto pode ser feito, sem se destruir a eficiência do mesmo, apresentandose as informações importantes de forma condensada na primeira página e construindo-se as informações pormenorizadas nas páginas subseqüentes. O leitor pode, então, ràpidamente, ganhar a informação significante apresentada no relatório, lendo apenas a primeira página. Se isto estimular suficientemente seu interêsse para fazer com que queira informações mais minuciosas elas acham-se disponíveis nas páginas subsequientes.

\subsection{GRÁFICOS SÃo MAIS EFICIENTES}

Sem dúvida o meio mais eficiente de se conseguir a atenção potencial do leitor de um relatório e de se transmitir a maior quantidade de informações para êle com o mínimo de seu tempo é através do uso de 
gráficos. Um bom gráfico pode proporcionar ao leitor mais informações em um instante do que êle poderia receber através de um longo estudo de uma tabela pormenorizada de números.

Usando-se apenas uma ou duas linhas em um gráfico pode-se mostrar simultâneamente ao leitor qual a contribuição de qualquer elemento para a realização de seu plano de lucros, como ela tem sido, em que direção está se movendo, a que taxa, seu padrão sazonável e muitas outras características que seriam quase que impossível de serem transmitidas a não ser gràficamente.

Sendo essencial uma figura, um gráfico pode proporcionar não sòmente a grande vantagem que as figuras têm sôbre textos ou números em conseguir manter a atenção das pessoas, como também pode dramatizar a informação apresentada que, provàvelmente, seria impossível por outro meio de comunicação. Através de uma seleção habilidosa do tipo de gráfico e da escala a ser utilizada para se apresentar os dados no gráfico, mudanças, tendências e variações que poderiam ser mal vistas, ou observadas de forma não significativa numa apresentação tabular normal, podem ser feitas de modo a aparecer muito significativas. De fato, as oportunidades de dramatização proporcionadas pelos gráficos são tão grandes e tão fàcilmente utilizadas que elas freqüentemente tentam àquele que faz os gráficos a ser menos do que honesto, ou ao menos justo na apresentação de sua informação.

Uma das técnicas de dramatização questionável mais comumente empregadas é de se mostrar apenas a metade superior ou menos de uma faixa do gráfico. Isto pode fazer com que um aumento ou uma diminuição menor pareça ser muitas vêzes maior do que realmente o é. Embora não se recomende tal dramatização excessiva, isto mostra, claramente, o grande poder que pode ser adicionado à informação apresentada através do uso de gráficos.

Embora se reconheça a vantagem de gráficos como um meio de apresentação, o seu uso em relatórios de planejamento de lucros mensais rotineiros pode parecer não prático e custoso. Gráficos realmente simples, mas eficientes, podem ser preparados e duplicados com pouco mais esfôrço do que uma apresentação tabular de números. Não é necessário que se entregue a um artista para preparar gráficos coloridos, elaborados como se vê em revistas. Usando-se materiais de gráficos e equipamentos de cópias agora disponíveis, qualquer funcioná- 
rio pode preparar uma série excelente de gráficos com muito pouco esfôrço ou tempo.

Uma biblioteca de gráficos principais pode ser mantida, requerendo apenas a extensão de uma linha a mais a ser marcada e duplicada num relatório mensal. Selecionando-se alguns dêstes gráficos cada mês, é possível criarem-se relatórios de uma variedade infinita, que ressaltam as áreas da administração necessitando de atenção.

\subsection{A IMPORTÂNCIA DO TEMPO}

Uma característica da eficiência de um relato, que não é do relatório em si, mas que pode ser até mais importante, é o tempo. Nada subtrairá tanto de um relatório de outra forma bom, do que apresentálo vários meses após a mais recente informação que contém. Particularmente, como o objetivo de um bom relatório de planejamento de lucros deveria ser o de estimular a ação corretiva, é essencial que a informação que apresente a necessidade de tal ação seja mostrada antes que seja muito tarde para iniciá-la. A razão para muitas demoras nos relatórios é a ênfase demasiada na importância de exatidão em se relatar as figuras reais de um período contábil em particular. E notável quão frequientemente a data de apresentação de um importante relatório é estabelecida com base na data em que haja disponibilidade de dados relativamente não importantes no relatório.

Freqüentemente um controlador quase que vai à guerra com uma companhia de serviços porque a data de mandar suas contas causa a demora de uma semana a mais em seus relatórios. Solucionar o problema estimando-se a conta ou relatando-a no mês seguinte são alternativas que parecem violar alguma ordem sagrada. Em bancos, como uma proporção muito grande das receitas e das despesas são feitas, geralmente, numa base de rateio, há ainda razão para se deixar que o tempo em que pequenos dados adicionais são informados atrasem a edição dos relatórios.

\subsection{REUNIÕES DE REVISÃo EFICIENTES}

As mesmas características de relatórios eficientes também caracterizam as reuniões de revisão eficientes. De fato, as informações discutidas nas reuniões de revisão podem ser apresentadas exatamente como o são no sistema de se reportar o plano de lucros. 
Como uma das maiores vantagens de uma reunião de revisão é a oportunidade que proporciona de se discutir as informações que estão sendo apresentadas, é essencial que se tenha a atenção de todos focalizada sôbre a mesma informação, ao mesmo tempo. Se muitos dos que estão assistindo a uma reunião estão lendo a página 10 , enquanto que se está discutindo a informação na página 5 , muito do benefício da reunião está se perdendo. A melhor maneira de se prender esta diluição de atenção é projetando-se a informação que está sendo discutida numa tela. Desta forma, não sòmente pode-se manter a atenção sôbre a informação, como também uma ênfase adicional pode ser conseguida apontando-se os dados ou as linhas específicas no gráfico.

$O$ método do projetor. Assim como no caso de se preparar gráficos, não é necessário envolver-se num processo elaborado, ou gastar-se muito tempo e dinheiro para se preparar a apresentação para a projeção. O método simples é utilizar-se de um projetor opaco no qual as páginas de um relatório podem ser mostradas numa tela. O único requisito absoluto é que a informação mostrada na tela possa ser lida por todos na sala.

O método de se discutir a informação apresentada na tela também pode ser importante em adicionar ou subtrair à eficiência de uma reunião de revisão, embora um dos métodos mais comuns de se conduzir tais reunióes seja fazer com que o indivíduo que prepara a informação, geralmente o controlador, faça a apresentação. Muito pode se ganhar se o administrador da divisão ou do departamento que se está analisando, fizer a apresentação.

Ao apresentar os resultados operacionais e as previsões para a sua divisão, um administrador sente-se, geralmente, com maior responsabilidade sôbre a informação que está apresentando e compreende-a mais profundamente; e, provàvelmente, estará melhor preparado para responder quaisquer questôes concernentes ao comportamento de sua divisão, podendo ser questionado por um administrador superior.

\subsection{O MANTER A ATENÇÃO DA AUdIÊNCIA}

Além da apresentação e discussão dos dados do comportamento do plano de lucros, outras apresentações de interêsse e importância, tais como a comparação com os concorrentes, previsão de condições econômicas gerais, análises especiais, etc., podem ser adicionadas periò- 
dicamente, ao programa de revisão. Isto, geralmente, aumenta o interêsse dos encontros e, portanto, melhora sua habilidade em se conseguir a atenção dos participantes.

A habilidade do sistema de acompanhamento em manter a atenção de todos os administradores focalizada sôbre a realização de seus lucros planejados, é a chave do sucesso de todo o esfôrço de planejamento de lucros. Para se manter êste interêsse e atenção vivos é essencial que se procure, contìnuamente, meios de melhorar tanto os relatórios como as reuniões. Isto é uma tarefa na qual alguém jamais deveria esperar ter atingido o último estágio.

Qualquer relatório ou reunião, não importa quão perfeitamente estruturado, se mantido imutável por um longo período de tempo perderá muito de sua eficiência. Portanto, não se deve subestimar o fato de que a habilidade de melhorar contìnuamente os lucros será influenciada, geralmente, pela habilidade de se melhorar, contìnuamente, a forma de relatar o plano de lucros.

A nova CONJUNTURA ECONOMICA permanece tradicional. É ainda objetiva, precisa, imparcial e atualizada. Tudo como antes. Ficou, é claro, mais bonita, moderna, e seu formato é maior. Para facilitar as consultas e tentar, depois, o leitor a deixá-la em cima da mesa, só para enfeitar.

Uma publicação da Fundação Getúlio Vargas. Procure nas bancas ou escreva para a Praia de Botafogo 188, Caixa Postal 21.120, ZC-05, Rio de Janeiro, GB. 